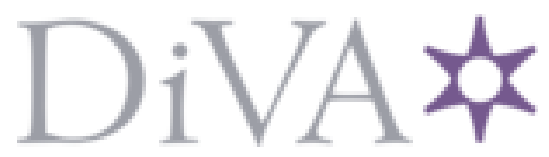

http://www.diva-portal.org

\title{
Postprint
}

This is the accepted version of a paper published in International Journal of Older People Nursing. This paper has been peer-reviewed but does not include the final publisher proof-corrections or journal pagination.

Citation for the original published paper (version of record):

Isaksson, U., Åström, S., Hällgren Graneheim, U. (2013)

Being flexible and tuning in: professional caregivers' reflections on management of violent behaviour in nursing homes.

International Journal of Older People Nursing, 8(4): 290-298

http://dx.doi.org/10.1111/opn.12005

Access to the published version may require subscription.

N.B. When citing this work, cite the original published paper.

Permanent link to this version:

http://urn.kb.se/resolve?urn=urn:nbn:se:umu:diva-60531 


\section{BEING FLEXIBLE AND TUNING IN: PROFESSIONAL CAREGIVERS' \\ REFLECTIONS ON MANAGEMENT OF VIOLENT BEHAVIOUR IN \\ NURSING HOMES}

Running Title: Managing violent behaviour in nursing homes

Ulf Isaksson, PhD, MHN, Postdoctoral Research Fellow, Senior Lecturer, Department of Nursing, Umeå University, Sweden

Sture Åström, PhD, RNT, Professor, Department of Nursing, Umeå University, Sweden, and Department of Caring Health and Culture, University West, Trollhättan, Sweden

Ulla Hällgren Graneheim, PhD, RNT, Associated Professor, Department of Nursing, Umeå University, Sweden

\section{Correspondence:}

Ulf Isaksson, Department of Nursing, The Caring Science Building, Umeå University, 90187 Umeå, SWEDEN

E-mail: ulf.isaksson@nurs.umu.se Phone: +46 (90)786 9186; Fax: +46 (90)786 9169

\section{AUTHORS' CONTRIBUTIONS:}

Study design: UI \& SÅ; Data collection: UI; Data analysis: UI \& UHG; Manuscript preparation: UI, UHG, SÅ. 


\section{ABSTRACT}

Background: Violence towards caregivers in the care of older people is a challenge attracting increasing attention in nursing research. However, studies that focus on the approaches caregivers in nursing homes resort to and how they manage everyday care situations involving threats and violent situations are relatively few.

Aims and objectives: This qualitative, descriptive study aimed to illuminate professional caregivers' reflections on managing residents' violent behaviour in nursing homes.

Methods: The study was based on 41 interviews in which the caregivers reflected on their own courses of action in violent situations. The interviews were subjected to qualitative content analysis.

Results: This study showed that caregivers were flexible and in tune with the resident by averting and defusing threatening and violent situations. The caregivers tried to give care in line with the residents' condition, control their own spontaneous reactions, and interpret the residents' reactions as communicative signs indicating how they should interact with the resident in the situation. As a last resort, when previous approaches had been unsuccessful, the caregivers took a firm stand with the residents' best interests in mind. The caregivers confronted the resident and the violent behaviour more directly, however, with respect and the residents' best interests in mind.

Conclusions: In order to be flexible and in tune with residents it is important to know the residents' personal histories. This may mean involving stakeholders, such as family members and friends, in the care of residents with violent behaviour. However, it is also important that caregivers be aware of the risks when interpreting residents' behaviour in light of their personal histories since for example relatives experiences is subjective and the information may give the caregivers preconceived ideas about the resident. 


\section{Implications for practice:}

- These findings illuminate how caregivers successfully can manage threatening and violent behaviour in nursing homes by being flexible and tuning in with the resident but also by taking a firm stand with the residents' best interest in mind.

- We believe that it is important to involve stakeholders in the care of threatening and violent residents in nursing homes since it is important to get information on the residents' personal history.

- However, there are risks when interpreting residents' behaviour in light of their personal histories since relatives experiences may be subjective and the information may give the caregivers preconceived ideas about the resident.

Keywords: Managing strategies, nursing home, professional caregivers, violent behaviour. 


\section{INTRODUCTION}

Violent behaviour towards professional caregivers has been reported from different countries and in different contexts (Lundstrom et al. 2007, Mullan \& Badger 2007, Isaksson et al. 2011, Scott et al. 2011). Studies have shown that the prevalence of violent behaviour among residents in nursing homes ranges from $11 \%$ to $68 \%$ (Zuidema et al. 2007, Isaksson et al. 2008a, Kverno et al. 2008, Shaji et al. 2009). Violent behaviour often complicates nursing care, and most incidents occur during morning or evening duties when the caregiver is required to work closely with the resident assisting with personal care, e.g. helping the resident with meals and personal hygiene (Åström et al. 2004). Åström et al. (2004) and Isaksson et al. (2008) reported that how caregivers deal with violence varies from person to person and depends upon their age and degree of experience. They also found that older and more experienced caregivers are more successful in managing residents with violent behaviour.

Studies have reported various ways of managing violent behaviour in the care of older people. Karlsson et al. (2001) and Gudjonsson et al. (2004) reported the use of seclusion, physical restraint, and medication. Duxbury and Whittington (2005) found that the use of medication and seclusion was supported by staff but not by patients, while both parties thought the use of restraint was inevitable. Several guidelines have also addressed the problem (e.g., Occupational Safety and Health Administration 2004, Lundstrom \& Isaksson 2010). These guidelines, however, most often aim to prevent escalation of the violent behaviour. If these recommendations fail, restraint, medication, or isolation is often advocated, although previous research has shown limited supporting evidence for such actions (Cowin et al. 2003). 
Previous studies have focused mainly on the management of threats and violent behaviour in psychiatric care (Carlsson et al. 2000, Bisconer et al. 2006, Daffern et al. 2006, McDonnell et al. 2008). Studies that focus on the approaches caregivers in nursing homes resort to and how they manage everyday care situations involving threats and violent situations are relatively few. It is important to gain a deeper understanding of caregivers' management of violent behaviour in the care of older people as this could provide a foundation for interventions to improve caregivers' competence to prevent and manage violent behaviour.

The aim of this study was to illuminate professional caregivers' reflections on management of residents' violent behaviour in nursing homes.

\section{MATERIALS AND METHODS}

\section{Research Context}

Three nursing homes in a municipality in northern Sweden were included. One nursing home had six units of between 28 and 32 residents per unit, the second nursing home had four units with 16 residents per unit, and the third nursing home had four units with eight residents each.

The residents were between 53 and 99 years old (mean $=82.4$, standard deviation [SD] $=8.9$ ) and $63.7 \%$ were women. The stay at the nursing home ranged between 1 and 16 years $($ mean $=2, \mathrm{SD}=2.2)$. The most common diagnoses, according to the ICD-10 (World Health Organization, 1994), were circulatory diseases (49.1\%), mental illness and behavioural disorders $(46.2 \%)$, and diseases of the nervous system (13.2\%). The residents' cognitive ability, assessed with the Mini Mental State Examination (Folstein et al., 1975), varied between 0 and $30($ mean $=9.7, \mathrm{SD}=9.2)$ and their functional ability in activities of daily 
living (ADL), assessed on the Barthel ADL index (Wade 1992), ranged from 0 to 18 (mean = 4.1, $\mathrm{SD}=4.5)$.

\section{Participants}

Based on type of institution, age, occupation, and exposure to violence, a purposeful sample of 41 female caregivers was selected. The participating caregivers ranged in age from 20 to 59 years $($ median $=45)$ and their work experience in the care of older people ranged from 1 to 39 years (median $=10)$. Eight nursing assistants, 23 enrolled nurses, and 10 registered nurses were included.

\section{Interviews}

This study is a part of a larger project. During the data collection, we refrained from giving a definition of violence as the main focus was to explore the caregivers' subjective perceptions of violence (Isaksson, 2008). However, to ensure that the caregivers began by discussing the same type of scenario, the participants were presented with the following

vignette: 'A female caregiver is helping a male resident in the lavatory. Suddenly he screams loudly, shakes his fist, calls her derogatory names, and scratches and pinches her until a colleague comes to her aid.' The caregivers were asked to describe how they would act in a comparable situation and to reflect upon the management of violent situations in nursing homes. During the interviews probing questions such as 'Can you describe how you usually handle situations like this?', 'Are there any alternatives?', and 'Can you tell more about your thoughts?' were asked in order to clarify the caregivers' reflections. The interviews were conducted in direct proximity to the workplace by the first author and lasted between 17 and 54 minutes $($ median $=25)$. The interviews were tape recorded and transcribed verbatim. 


\section{Data analysis}

The text was analysed using qualitative content analysis, inspired by Graneheim and Lundman (2004). Content analysis is a method that systematically analyses written or verbal communication (Krippendorff 2004) and focuses on both subject and context, with attention to differences and similarities between and within parts of the text (Graneheim and Lundman 2004).

The interviews were read several times to gain a basic understanding of the content. Text corresponding to the aim (approximately $1 / 4$ of the transcribed text) was identified and separated, constituting the unit of analysis. The remaining text, which concerned descriptions and reasons for violent behaviour, was analysed previously and is presented elsewhere (Isaksson et al. 2008b, Graneheim et al. 2012). The text was divided into meaning units that were condensed, with their core meanings preserved, and labelled with codes that described the content. The codes were compared for differences and similarities and sorted into seven categories. To arrive at an interpretation of its underlying meaning, each category was read, critically analysed, and compared, and three sub-themes and two themes were formulated. According to Graneheim and Lundman (2004), a theme can be seen as a thread of meaning running through categories on an interpretative level.

To obtain trustworthiness, categories and themes were discussed among the authors, resulting in consolidation of the findings. By presenting the findings with quotations, we enable the reader to judge the authenticity of our findings and conclusions.

\section{Ethical considerations}

The study was reviewed by the Ethics Committee at the Medical Faculty of the University of Umeå (DNR 98-239; DNR 01-023). The local authorities in the community and the care managers at each unit received information about the study and agreed to the study implementation. All participants were given written and oral information prior to the 
interview and were assured that all data would be treated confidentially, that their participation was voluntary, and that they could choose to cancel their participation at any time without giving any reason. Informed consent was attained before the interview started.

\section{RESULTS}

The caregivers in this study managed violence by being flexible and in tune with the residents. They averted and defused threatening and violent situations. As a last resort, they took a firm stand with the residents' best interest in mind and confronted the violent situation. The categories, sub-themes, and themes from the interviews are presented in the Table.

\section{Insert Table about here}

\section{Being flexible and in tune with the resident}

We found that the caregivers managed violent behaviour by averting threatening situations and defusing violent situations. The caregivers tried to give care in line with the residents' condition, control their own spontaneous reactions, and interpret the residents' reactions as communicative signs indicating how they should interact with the resident in the situation. This way of managing the situation was connected to the caregivers' insight that the residents - despite their illness - had the ability and will to make their own decisions and maintain their autonomy even though the circumstances they were living in could be frustrating.

\section{Averting threatening situations}

The subtheme, averting threatening situations included the categories of giving time and space, calming the resident down, and distracting the resident. The caregivers described these approaches as first steps in averting a threatening situation. 


\section{Giving time and space}

The caregivers said that one way to avert threatening situations was to give the residents time and space to act out their frustration. They waited and watched in order to find an opportunity to continue helping the resident with the activity at a later stage. One caregiver said, ' $\ldots$ just be quiet while he goes on, and let him get his aggression out, and yes, just wait ...' The caregivers also stressed the importance of leaving residents alone for a while, just to give them a chance to get over the situation. 'And so he is left alone - it does not even need to be for an especially long time - and then we can come back after a few moments ... and then he is the world's nicest person again ...' Through waiting and allowing residents time and space to process the situation themselves, caregivers' were able to influence residents in a positive way.

\section{Calming down}

The caregivers said that a common way of averting threatening situations was to try to calm the resident down. It was very important that they were prepared for the interaction to be able to alleviate threatening situations: ' $\ldots$ you cannot just shout and scream, then it becomes quite wrong, the situation becomes worse, you must try to be calm and sensible and, yes take it carefully ...' They also expressed the importance of touch in calming the residents down. They described various ways to help upset residents to calm down, to redirect them, and then to be able to go on with the task that the caregiver had been entrusted with.

You try to put your arm around their shoulders, to take their hands ... be close to them, hug them, and say that this will go well, it's only me who is here, we are going to shower now, it's nothing that is dangerous. Perhaps put a towel on him, dry him so that he does not become cold and irritable ... somehow calm him down. 
The caregivers said that their own calm mood and self-control rubbed off on the residents and that they eventually calmed down; 'If I just stand there and stay calm ... eventually he calms down and then I can help him ... My calm rubs off.'

\section{Distracting}

The caregivers said that distracting the resident is often a successful approach to dealing with a potentially threatening situation. Caregivers used both verbal and physical distractions.

I usually sing a little, talk a little bit. You could say I distract them. I talk about something I know the resident is interested in. I think it is successful many times, but not always. You learn in time, you discover what works and does not.

The conversations often involved things the residents had done or remembered from their earlier lives that the caregiver thought may be of interest to them. The caregivers also said that soft music could be calming for the residents. Another distraction was to give the resident coffee or something to eat. Caregivers emphasized that such distracting interventions were best used individually and that they differed from resident to resident.

\section{Defusing violent situations}

This subtheme is based on the categories of handing over to a colleague and postponing the task, approaches caregivers said they used when they had not succeeded in averting the threatening situation.

\section{Handing over}

The caregivers said that another approach they used when a conflict arose was to let a colleague take over the task.

Well... one thing may be switching between each other. It is not that the residents and staff are always on a collision course, but on that day, perhaps it does not work correctly. However, if you ask a colleague, it may go much better. It may be 
that this other person could explain better what to do, so that the resident understands better.

An explanation for this was that the chemistry between the caregiver and the resident was not always the best or could change from day to day due to the resident's or caregiver's emotional state.

If it does not work, I go to a colleague and ask if she will swap with me, maybe he [the resident] cannot tolerate me just then. Then someone else can take over. ... I have seen it several times - that you replace one caregiver with someone else that the resident accepts.

In order to decide how best to respond to their violent behaviour, the caregivers said that they usually were helped by gathering information from relatives on the residents' history. However, sometimes this information included stories of previous violence towards close relatives. This contributed to feelings of disgust and caused gave the caregivers preconceived ideas towards the residents; 'I think I would have been more tolerant if I knew he had behaved normally with his wife and his daughter... And of course, it becomes a vicious circle, it's hard when you know how he has behaved and been before. You pull back instinctively, you defend yourself...' In such situations the caregivers sometimes asked someone more experienced or physically stronger to step in. If there was a resident known for repeated violent behaviour, the caregivers took turn caring for this person. One caregiver said, 'We usually take turns when it becomes too difficult,' but as a last resort, when the caregivers felt that they could no longer handle the situation, they called for help:

'And if that does not work, then I must... first ensure that he is secure and that he does not go away somewhere, and then find help from someone else. Or I press the alarm button so that someone else will come to my rescue.' 


\section{Postponing the task}

Caregivers described an approach in which they avoided ending up in a situation of potential violence by postponing the task temporarily so as not to expose themselves or the resident to unnecessary physical or mental harm: 'And sometimes we just finish the job. ...We do not wash him today. We do not do the morning hygiene. We just exit and leave in peace. Yes, just for the moment ...we skip it.'

Other ways of avoiding violence included maintaining enough physical distance to be out of range of harm: 'And usually, you keep some distance or are more cautious. Keep some physical distance, yes. We know who kicks and punches, and we have to keep them away from us.' As a last alternative, the caregivers said that they could leave the situation.

If it becomes really serious and I believe there is a great risk that I will be seriously injured, then I have to get out of there... leave the resident alone. I have to try to save myself... I have to assess every case: is there a serious risk for me to get hurt?

The caregivers said that one way to avoid this was to always work in pairs when caring for a violent resident.

You should not be alone; you should never go alone to a person who is violent... always help each other. If I get punched, then my college can call for help, or if the resident becomes violent, we can help each other... You should always work in twos when you are helping threatening people, never alone...

\section{Taking a firm stand with the residents' best interest in mind}

As a last resort, when previous approaches had been unsuccessful, the caregivers took a firm stand with the residents' best interest in mind and confronted the violent resident more directly. However, they tried to do this with respect and the residents' best interests in mind. 


\section{Confronting violent situations}

This subtheme revealed the two categories: carrying on with the task and setting limits. This was described as the last step when all other approaches had been unsuccessful.

\section{Carrying on with the task}

The caregivers said that they sometimes completed the care situation despite the fact that the patient was reluctant and aggressive. However, this was done based on ethical reasoning. The caregivers described how when a resident could no longer distinguish between good and bad, staff would step in and make decisions for them.

I weigh good against evil, what is best for the patient in this situation... he must be terribly worried and anxious.... In this situation, the resident does not know what is best for him. Then we must help, help him with what we can and what we think is best for him... / sigh /. But when it has gone so far as to the need for a calming tablet, then I do not feel bad - I do it for his own good, for him to feel good. Yes, he doesn't know what is best for him. It is what I will do, as a last resort, when there is nothing left to do but to restrain him.

In order to manage this, the caregivers said that they would shield themselves from the situation and just finish the assigned task:

He talked, he swore, and he pinched me, but I was not bothered about it, after a while I did not hear him and continued showering him. I just shut him out... I had to do it. You do what you have to do.'

\section{Setting limits}

The caregivers described that they used this course of action to try to get the patient to understand what was happening in the situation. They said that the residents may be experience the situation as less intimidating if they understood it and violence may therefore 
be avoided. The caregivers also explained that they used this approach when they felt that they had had enough of the situation.

No, but if a lot of unpleasant words start to pour out, then you can try to say in a friendly way, something like, 'There are words I do not tolerate hearing.' Say in a normal tone that I do not accept to be called this and this... Inform the resident in a friendly way of course.'

The caregivers said that they were proactive in informing the residents about how activities should be carried out and at the same time setting limits on what was permitted. They also said that they made it clear what was allowed and what was not. 'I say what I think, "You do not behave like this!", and if it is well marked, there's nothing wrong with it, for they should not do this...' The caregivers also said that other ways of setting limits were to restrain or sedate the resident: 'It depends. If he is sitting on a chair, maybe I can attach a belt or something... then if he starts screaming or punches and scratches, then I think he should have some medication...'

\section{DISCUSSION}

The findings of this study showed that caregivers used different approaches to protect themselves and the residents when managing threatening and violent behaviour from residents in nursing homes. We found that the caregivers were flexible and in tune with the resident by averting threatening situations and defusing violent situations. They also took a firm stand, however, with the residents' best interest in mind.

Being flexible and in tune with the resident and having the courage to complete difficult tasks require that the caregivers have a sense of timing about when to use various approaches and when to shift between them. Nursing literature often focuses more on emotional attunement than on timing. Kitwood (1997) argued that timing is important in dealing with 
people with dementia and responding to their signals, since they often have a reduced capacity to interpret and understand actions and verbal information. Therefore, the caregiver has a responsibility to act with clarity and caution. Abramowitz (2008) argued that caregivers who can tune in to the smallest nuances in a resident's behaviour at any given moment and can relate to each resident as a person can also best manage challenging behaviours.

In the first subtheme, averting threatening situations, the caregivers adopted an attitude of fending off confrontation, and they were cautious and gentle in the situation. The caregivers allowed the residents to act and to speak, and they gave the resident time and space to adjust to the situation. Baker et al. (2006) found that by taking a 10 second break each 20 seconds, caregivers were able to reduce residents' aggressive behaviour in connection with the bathroom routine. Furthermore, Foley et al. (2003) found that an intrapersonal approach with a focus on verbal distraction calmed aggressive residents, while we found that caregivers with a calm mood and self-control were able to calm the residents down. The caregivers said that if they were having a bad day this could set off a mood of irritation among the residents. This is in line with Graneheim et al. (2012), who reported that residents often became a mirror of the caregivers' own moods; if the caregiver was in a bad mood, the resident would be, too. Hill and Petit (2000) emphasized that verbal de-escalation should be the first approach to any aggressive patient, and this includes any verbal and nonverbal responses the caregiver can use to neutralize or reduce a potentially threatening situation. We also found that in many cases caregivers used body contact, ranging from handholding and gentle pats to short hugs. Carlsson et al. (2000) argued that intention is important in the use of touch, which allows caregiver to show the residents their goodwill.

In the second subtheme about defusing violent situations caregivers described how they chose to pull back from the potentially violent situation and return to neutral positions. The caregivers tried to distract the resident's attention away from the upsetting nursing situation, 
or they left the resident or the entire situation to a colleague and removed themselves from the situation. This repositioning was well thought out and based on their own experiences the shared experiences of the working groups. Graneheim et al. (2001) also found that caregivers would withdraw and wait for the resident to calm down. Furthermore, the caregivers in our study described how they handed over the situation to a colleague when the personal chemistry between the caregiver and the resident did not work. This is in line with Graneheim et al. (2012) who also found that the personal chemistry between caregivers and residents could be a source of provocation and trigger violent behaviour.

In the third subtheme confronting violent situations, the caregivers took a firm stand, although with the residents' best interest in mind. They tried to use strategies that had been successful previously to shorten the time they needed to be in physical proximity to the resident. This meant that sometimes they physically held the resident to perform the caring task as quickly as possible and then leave the resident alone. This is the least favourable approach. Skovdahl et al. (2003) found that aggression occurred in situations when the caregivers and the residents had no dialogue with each other, which led to a struggle for power. The caregivers paid no attention to the residents' aggression in these cases and just carried on with the task. This resulted in even more aggression and the caregivers' use of restraints to hold the resident. The caregivers in our study, however, entered the violent situation with vigour and intensity and with an ethical outlook informing their actions. This is in accordance with findings by Graneheim et al. (2001), who found that even when caregivers had to restrain a physically aggressive resident, they tried to do this in a respectful manner and to keep the resident's autonomy in mind. Sometimes, however, residents' privacy and autonomy were violated when caregivers felt such actions was necessary for the resident's or fellow residents' security. 
To assess which approach would be most appropriate in a certain situation, it is most helpful to be familiar with the particular resident's personal history. Abramowitz (2008) argued that by learning about each person's background and lifestyle before the outbreak of the illness and the person's likes, dislikes, and medical history, the caregivers can become skilled observers with an ability to interpret and predict behaviour such as violence. One way to accomplish this is by using person-centred care (Kitwood, 1997), in which the personal history is gathered with the help of relatives or other persons who know the individual well. According to person-centred care, there is no such thing as 'disturbing behaviour'. Abramowitz (2008) asserted that all behaviour should be viewed as an attempt at communication, and it is therefore a challenge to the caregivers to discover what the patient trying to communicate.

However, there could be several risks in interpreting residents' behaviour in light of their personal history. Relatives' experiences of the residents' background are subjective and not always based on complete knowledge of the residents' entire life situation. Different relatives may also perceive different sides of the resident's personality and therefore contribute confusing and conflicting information about what is best for the resident. The residents' preferences may also have changed over time and the relatives' views may no longer be valid. Furthermore, knowing the resident's personal history might spawn preconceived and incorrect ideas about the resident among the caregivers. This is confirmed by Isaksson et al. (2009) who in an earlier study found that caregivers in nursing homes had preconceived ideas about a resident with a history of violent behaviour towards women. The caregivers were disgusted; they became overwhelmed by caution, anger, and revulsion, and resigned to the fact that they had to care for violent residents whether they liked it or not. 


\section{Methodological discussion}

Because a large majority of caregivers in the nursing homes were women (The Swedish Institute, 1999), it was decided that the interviews should be conducted only with female caregivers. The findings are still transferable to similar contexts in other areas of the care of older people because the contextual matters can be considered comparable.

Bruffaerts et al. (2004) showed that male residents often exhibited more threats and acts of violence than female residents, which is one reason why we used a vignette that described a male person who acted violently. However, even if the vignette had been gender neutral or featured a female resident, we do not believe it likely that the caregivers' reflections on the management of violent situations would differ considerably.

The number of participants in our study allowed a broad variety of descriptions of the management of violent behaviour. We also regard it as a strength that one person with considerable experience of working in psycho-geriatric care, and keen awareness of both the caregivers' work situation and the internal linguistic culture, interviewed all participants. This added genuine authenticity and trust between the interviewer and the participants and added depth and quality to the interviews. However, as the interviewer himself has personal experience of being exposed to violent behaviour, there was a risk that he believed that there was a shared understanding between the caregiver and the interviewer, although this may not have been the case (cf. Mishler, 1986). Therefore, he may have refrained from asking relevant and probing follow-up questions.

During the analysis, the codes, categories, and themes were discussed among the authors to enhance the credibility of the interpretations (c.f. Graneheim \& Lundman, 2004). According to Krippendorff (2004), a text does not contain one specific meaning, but the most probable meaning can be adduced from a certain perspective. Thus, the result of this study is 
one of many possible interpretations of the caregivers' reflections on managing residents' violent behaviour in nursing homes.

\section{Conclusion and implications for practice}

This study showed that caregivers were mostly flexible and in tune with the resident, and as a last resort, that they showed courage by completing difficult tasks in the face of threatening and violent situations. To be flexible and in tune with residents, it is important to know the residents' personal history. One way to accomplish this is to involve stakeholders, such as family members and friends, in the care of residents with violent behaviour.

Furthermore, developing individual care plans, taking the residents' personal history into account, can prevent an inconsistent approach and ensure that confrontation is a last resort.

However, it is equally important to be aware of the risks inherent in interpreting the residents' behaviour in light of their personal history and information from people close to them. Therefore, to prevent the risks, it is important that the caregivers receive support in order to provide non judgemental person-centred care irrespective of an individual's past history.

We believe that the need for further research is great. In this study, no male caregivers were included because very few employed caregivers are male. With a growing proportion of male caregivers, however, and caregivers and residents from other countries, used to other cultures, it would be important in future studies to illustrate how these caregivers of both sexes and various cultural backgrounds interpret and manage situations of challenging and violent behaviour in the care of the older people.

\section{ACKNOWLEDGEMENTS}

This study was supported by grants from Äldrecentrum [Field Research Centre for the Elderly], Västerbotten, Sweden, Demensförbundet, Stiftelsen Lions forskningsfond för 
åldersrelaterade sjukdomar and the Strategic Research Programme in Care Sciences, Umeå University and Karolinska Institutet.

The authors would especially like to thank the caregivers for their participation in the study and Thomas Andersson, BSc, RN and Svante Mattsson, BSc, RN, for their contributions.

\section{REFERENCES}

Abramowitz, L. (2008). Working with advanced dementia patients in a day care setting. Journal of Gerontological Social Work, 50, 25-35.

Åström, S., Karlsson, S., Sandvide, A., et al. (2004). Staff's experience of and the management of violent incidents in elderly care. Scandinavian Journal of Caring Sciences, 18, 410-416.

Baker, J. C., Hanley, G. P. \& Mathews, R. M. (2006). Staff-administered functional analysis and treatment of aggression by an elder with dementia. Journal of Applied Behavior Analysis, 39, 469-474.

Bisconer, S. W., Green, M., Mallon-Czajka, J. \& Johnson, J. S. (2006). Managing aggression in a psychiatric hospital using a behaviour plan: A case study. Journal of Psychiatric and Mental Health Nursing, 13, 515-521.

Bruffaerts, R., Sabbe, M. \& Demyttenaere, K. (2004). Attenders of a university hospital psychiatric emergency service in Belgium - general characteristics and gender differences. Social Psychiatry and Psychiatric Epidemiology, 39, 146-153. 
Carlsson, G., Dahlberg, K. \& Drew, N. (2000). Encountering violence and aggression in mental health nursing: A phenomenological study of tacit caring knowledge. Issues in Mental Health Nursing, 21, 533-545.

Cowin, L., Davies, R., Estall, G., Berlin, T., Fitzgerald, M. \& Hoot, S. (2003). De-escalating aggression and violence in the mental health setting. International Journal of Mental Health Nursing, 12, 64-73.

Daffern, M., Mayer, M. \& Martin, T. (2006). Staff gender ratio and aggression in a forensic psychiatric hospital. International Journal of Mental Health Nursing, 15, 93-99.

Duxbury, J. \& Whittington, R. (2005). Causes and management of patient aggression and violence: Staff and patient perspectives. Journal of Advanced Nursing, 50, 469-478.

Foley, K. L., Sudha, S., Sloane, P. D. \& Gold, D. T. (2003). Staff perceptions of successful management of severe behavioural problems in dementia special care units. Dementia, $2,105-124$.

Folstein, M. F., Folstein, S. E. \& McHugh, P. R. (1975). 'Mini-mental state'. A practical method for grading the cognitive state of patients for the clinician. Journal of Psychiatric Research, 12, 189-198.

Graneheim, U. H., Hörnsten, A. \& Isaksson, U. (2012). Female caregivers' perceptions of reasons for violent behaviour among nursing home residents. Journal of Psychiatric and Mental Health Nursing, 19, 154-161.

Graneheim, U. H. \& Lundman, B. (2004). Qualitative content analysis in nursing research: Concepts, procedures and measures to achieve trustworthiness. Nurse Education Today, 24, 105-112. 
Graneheim, U. H., Norberg, A. \& Jansson, L. (2001). Interaction relating to privacy, identity, autonomy and security. An observational study focusing on a woman with dementia and 'behavioural disturbances', and on her care providers. Journal of Advanced Nursing, 36, 256-265.

Gudjonsson, G. H., Rabe-Hesketh, S. \& Szmukler, G. (2004). Management of psychiatric inpatient violence: Patient ethnicity and use of medication, restraint and seclusion. The British Journal of Psychiatry, 184, 258-262.

Hill, S. \& Petit, J. (2000). The violent patient. Emergency Medicine Clinics of North America, $18,301-315$.

Isaksson, U. (2008). Våld mot vårdare i sjukhemsvård [Violence Towards Caregivers in Nursing Homes]: Medical Dissertations New Series No 1154. Umeå University.

Isaksson, U., Graneheim, U. H., Åstrom, S. \& Karlsson, S. (2011). Physically violent behaviour in dementia care - characteristics of residents and management of violent situations. Aging and Mental Health, 15, 573-579.

Isaksson, U., Graneheim, U. H. \& Åström, S. (2009). Female caregivers’ experiences of exposure to violence in nursing homes. Journal of Psychiatric and Mental Health Nursing., 16, 46-53.

Isaksson, U., Richter, J., Eisemann, M. \& Åström, S. (2008a). Exposure to violence in relation to personality traits, coping abilities, and burnout among caregivers in nursing homes: A case-control study. Scandinavian Journal of Caring Sciences, 22, 551-559.

Isaksson, U., Åström, S. \& Graneheim, U. H. (2008b). Violence in nursing homes: Perceptions of female caregivers. Journal of Clinical Nursing, 17, 1660-1666. 
Karlsson, S., Bucht, G., Eriksson, S. \& Sandman, P. O. (2001). Factors relating to the use of physical restraints in geriatric care settings. Journal of the American Geriatrics Society, 49, 1722-1728.

Kitwood, T. M. (1997). Dementia Reconsidered: The Person Comes First. Buckingham; Open University Press.

Krippendorff, K. (2004). Content Analysis: An Introduction to its Methodology, Thousand Oaks, CA: Sage.

Kverno, K. S., Rabins, P. V., Blass, D. M., Hicks, K. L. \& Black, B. S. (2008). Prevalence and treatment of neuropsychiatric symptoms in advanced dementia. Journal of Gerontological Nursing, 34, 8-15.

Lundstrom, M. \& Isaksson, U. (2010). Threats and Violence in Health Care - Guidelines [In Swedish: Hot och våld inom vården - riktlinjer]. In: Swedish Association of Local Authorities and Regions [Sveriges Kommuner och Landsting] (Ed). The Handbook for Healthcare [In Swedish: Handbok för hälso- och sjukvård]. Stockholm: InfoMedica.

Lundstrom, M., Saveman, B. I., Eisemann, M. \& Åström, S. (2007). Prevalence of violence and its relation to caregivers' demographics and emotional reactions: An explorative study of caregivers working in group homes for persons with learning disabilities. Scandinavian Journal of Caring Sciences, 21, 84-90.

McDonnell, A., Sturmey, P., Oliver, C., et al. (2008). The effects of staff training on staff confidence and challenging behavior in services for people with autism spectrum disorders. Research in Autism Spectrum Disorders, 2, 311-319. 
Mishler, E. G. (1986). Research Interviewing: Context and Narrative. London: Harvard University Press.

Mullan, B. \& Badger, F. (2007). Aggression and violence towards staff working with older patients. Nursing Standard, 21, 35-38.

Occupational Safety and Health Administration (2004). Guidelines for Preventing Workplace Violence for Health Care \& Social Service Workers. Washington DC: United States Department of Labor.

Scott, A., Ryan, A., James, I. \& Mitchell, E. (2011). Perceptions and implications of violence from care home residents with dementia: a review and commentary. International Journal of Older People Nursing, 6, 110-122.

Shaji, K. S., George, R. K., Prince, M. J. \& Jacob, K. S. (2009). Behavioral symptoms and caregiver burden in dementia. Indian Journal of Psychiatry, 51, 45-49.

Skovdahl, K., Kihlgren, A. L. \& Kihlgren, M. (2003). Dementia and aggressiveness: video recorded morning care from different care units. Journal of Clinical Nursing, 12, 888898.

The Swedish Institute (1999). The Care of the Elderly in Sweden. Stockholm: The Swedish Institute.

Wade, D. T. (1992). Barthel ADL Index. In: Wade, D. T. (Ed). Measurement in Neurological Rehabilitation. Oxford: Oxford University Press.

World Health Organization (1994). International Statistical Classification of Diseases and Related Health Problems : ICD-10, Geneva: World Health Organization. 
Zuidema, S. U., de Jonghe, J. F., Verhey, F. R. \& Koopmans, R. T. (2007). Neuropsychiatric symptoms in nursing home patients: factor structure invariance of the Dutch nursing home version of the neuropsychiatric inventory in different stages of dementia. Dementia and Geriatric Cognitive Disorders, 24, 169-176. 
Categories, sub themes and themes revealed during the analysis

Themes

Sub themes

Categories

Giving time and space

Averting threatening

situations

Calming down

Being flexible and in tune

with the resident

situations in mind

Taking a firm stand with

the residents' best interest

in mind
Defusing violent situations
Distracting

Handing over

Postponing the task

Carrying on with the task

Setting limits 